\title{
Haemophilus influenzae meningitis in Sweden 1981-1983
}

\section{B TROLLFORS,${ }^{*}$ B A CLAESSON,$\dagger \mathrm{K}$ STRANGERT, $\ddagger$ AND J TARANGER}

Departments of *Paediatrics and †Infectious Diseases, University of Göteborg, Östra Hospital, Göteborg and out patient departments of Paediatrics, ¥St Görans Hospital, Stockholm, and §Västra Frölunda Hospital, Västra Frölunda, Sweden.

SUMMARY Four hundred and seventy cases of meningitis caused by Haemophilus influenzae in children and 30 cases in adults were identified in Sweden between 1981 and 1983. The age specific incidence in the most susceptible age group (0-4 years) was 31/100 000/year (440 cases), which is higher than previously reported from Europe. A further 30 cases were seen in children aged 5-14. The risk of developing $H$ influenzae meningitis before the age of 15 was 1 in 669 . There were 11 deaths $(2 \%)$ and five cases of serious neurological sequelae among the children. Only 18 children (4\%) had predisposing diseases. All but one of the 294 strains of $H$ influenzae from children that had been serotyped were type $b$. Infections in adults differed from infections in children. Five of the adults died (17\%), 12 had important predisposing diseases, and at least six of the infections were caused by non-typable strains. It is concluded that research into the prevention of invasive $H$ influenzae infections in children should have high priority.

The incidence of Haemophilus influenzae meningitis in children aged less than 5 years has been comprehensively studied in the United States. The age specific incidence in this group varied between 19 and 71/100 000/year in the general population, ${ }^{1-3}$ but three groups of native Americans had high incidences: 173-409/100 000/year. ${ }^{145}$ The variations in incidence can be explained partly by racial and socioeconomic differences.

In contrast, little is known about the incidence of $H$ influenzae meningitis in children outside North America. Two studies from England reported incidences in children less than 5 years old of only 11 and 18/100 000/year, respectively. ${ }^{6}$ In The Netherlands, ${ }^{8}$ Finland, ${ }^{9}$ and a region of Sweden, ${ }^{10}$ the incidences were 22,27 , and 27/100 000/year, respectively, in the same age group.

Even though most $H$ influenzae infections occur in young children, several recent reports have shown that the organism may also be the cause of meningitis in older children and adults. ${ }^{7911-13}$ The present study aimed to estimate the incidence and mortality of $H$ influenzae meningitis in children and adults in Sweden.

\section{Patients and methods}

We attempted to identify all Swedish residents who had $H$ influenzae meningitis between 1 January 1981 and 31 December 1983. All departments of paediatrics, infectious diseases, internal medicine, and neurosurgery in Sweden were contacted about patients with $H$ influenzae meningitis. Case records of these patients were examined by the authors at hospitals covering more than $20 \%$ of the population. The information from the remaining hospitals was obtained from the respective clinicians; 482 patients with $H$ influenzae meningitis were identified.

Letters were then sent to all departments of clinical bacteriology and to the National Bacteriological Laboratory requesting that all patients in whom $H$ influenzae had been isolated from cerebrospinal fluid should be reported to us. Because some laboratories had not kept complete records for the period being studied, this search yielded only 360 patients, 17 of whom had not been found through the hospital search. Their case records were also examined. The departments of medicolegal medicine, where patients who die outside hospital have necropsies carried out, reported an additional patient with $H$ influenzae meningitis. Thus a total of 500 cases were found in 498 patients, as two patients had the disease twice at intervals of one and eight months, respectively. These episodes have been counted separately.

In 490 cases the diagnosis was confirmed by 
isolation of $H$ influenzae from cerebrospinal fluid and in one case by isolation of $H$ influenzae from the meninges and several other organs at necropsy. The remaining nine patients all had clinical meningitis and the cerebrospinal fluid was purulent. $H$ influenzae was isolated from blood in eight cases. From one, $H$ influenzae type $\mathrm{b}$ capsular antigen was detected in the cerebrospinal fluid by coagglutination and Gram negative rods were seen on microscopy of the cerebrospinal fluid.

Four of the adult patients described here have been included in a previous report. ${ }^{11}$ Sweden has three regions, one in the south with 12 counties, one in the middle with seven counties, and one in the north with five counties. Population data from the 24 counties were obtained from official statistics. ${ }^{14}$

\section{Results}

CHILDREN 14 YEARS OLD AND UNDER

The age distribution of the 470 patients who were 14 years old or younger is shown in table 1 . Of the 470 , 440 children $(94 \%)$ were younger than 5 years old, $272(58 \%)$ were younger than 18 months, and 17 (4\%) were younger than 3 months. There were 252 boys $(54 \%)$ and 218 girls $(46 \%)$.

The age specific incidence in five year intervals is

Table 1 Age distribution related to seroptype of isolate in 500 cases of $H$ influenzae meningitis

\begin{tabular}{ccllcc}
\hline Age & Type $b$ & Type $f$ & Non-typable & Unknown & Total \\
\hline Months: & & & & & \\
$0-2$ & 8 & 0 & 0 & 9 & 17 \\
$3-5$ & 33 & 0 & 0 & 22 & 55 \\
$6-8$ & 42 & 1 & 0 & 28 & 71 \\
$9-11$ & 46 & 0 & 0 & 13 & 59 \\
$12-14$ & 23 & 0 & 0 & 15 & 38 \\
$15-17$ & 22 & 0 & 0 & 10 & 32 \\
$18-20$ & 18 & 0 & 0 & 9 & 27 \\
$21-23$ & 16 & 0 & 0 & 10 & 26 \\
Years: & & & & & \\
2 & 39 & 0 & 0 & 24 & 63 \\
3 & 19 & 0 & 0 & 19 & 38 \\
4 & 7 & 0 & 0 & 7 & 14 \\
5 & 7 & 0 & 0 & 2 & 9 \\
6 & 4 & 0 & 0 & 4 & 8 \\
7 & 1 & 0 & 0 & 1 & 2 \\
8 & 2 & 0 & 0 & 2 & 4 \\
9 & 3 & 0 & 0 & 0 & 3 \\
$10-14$ & 3 & 0 & 0 & 1 & 4 \\
$15-19$ & 3 & 0 & 0 & 1 & 4 \\
$20-29$ & 2 & 0 & 0 & 1 & 3 \\
$30-39$ & 4 & 1 & 2 & 0 & 7 \\
$40-49$ & 1 & 0 & 1 & 1 & 3 \\
$50-59$ & 1 & 1 & 0 & 1 & 3 \\
$60-69$ & 1 & 0 & 1 & 3 & 5 \\
$70-79$ & 1 & 0 & 1 & 2 & 4 \\
$80-89$ & 0 & 0 & 1 & 0 & 1 \\
\hline & & & & &
\end{tabular}

shown in table 2 . The incidence in the most susceptible age group (0-4 years) was 31/100 000/ year. The incidences in the southern, middle, and northern regions of Sweden were 27, 37, and 27/ $100000 /$ year, respectively. The incidences in the two counties with the biggest cities-Stockholm and Göteborg-were 32 and 24/100 000/year, respectively.

Serotyping of the infecting organism was performed by latex agglutination or coagglutination in 294 of the cases in children $(63 \%)$. All strains but one were type $\mathrm{b} ; H$ influenzae type $\mathrm{f}$ was isolated from a child aged 6 months with no known predisposing diseases. The serotypes of the isolates from the two children with two episodes of $H$ influenzae meningitis were not known.

Only 18 children $(4 \%)$ had any predisposing disease: congenital brain disease $(n=10)$, traumatic head injury $(n=4)$, Down's syndrome $(n=3)$, and malignant lymphoma $(n=1)$. One infant aged 3 months had been born at a gestational age of 30 weeks. All 17 infants aged $0-2$ months were born at gestational ages of 37 weeks or more. Only one had a predisposing disease (encephalocele), and this child had a second attack of $H$ influenzae meningitis eight months later.

Eleven children (including two neonates) with no known underlying diseases died. Five children developed serious neurological sequelae, such as hemiplegia, diplegia, or tetraplegia, in combination with mental retardation, blindness, or epilepsy. The mean time spent in hospital was 12 days.

\section{PATIENTS 15 YEARS OLD AND OLDER}

There were 30 adults (6\% of all patients) aged between 17 and 82 years. Eleven were men and 19 women. Their ages and the serotypes of the isolates are shown in table 1 . The adults differed from the children in serotype distribution, predisposing diseases, and outcome. Of the 21 strains that were

Table 2 Age specific incidence (cases/100 000/year) of Haemophilus influenzae meningitis in Sweden 1981-1983.

\begin{tabular}{lllc}
\hline $\begin{array}{l}\text { Age } \\
\text { (years) }\end{array}$ & $\begin{array}{l}\text { Mean } \\
\text { population }\end{array}$ & $\begin{array}{l}\text { Documented } \\
\text { cases of } \\
\text { H influenzae } \\
\text { meningitis }\end{array}$ & $\begin{array}{l}\text { Age specific } \\
\text { incidence }\end{array}$ \\
\hline $0-4$ & 477461 & 440 & $30 \cdot 7$ \\
$5-9$ & 530926 & 26 & $1 \cdot 6$ \\
$10-14$ & 563927 & 4 & $0 \cdot 2$ \\
$0-14$ & 1572314 & 470 & $10 \cdot 0$ \\
15 and & 6752610 & 30 & $0 \cdot 1$ \\
over & & & $2 \cdot 0$ \\
\hline Total & 8324924 & 500 & \\
\hline
\end{tabular}


serotyped, only 13 were type b, two were type $f$, and six were non-typable. Predisposing diseases were known in 12 adults $(40 \%)$ and comprised head injury $(n=11)$ and acute lymphatic leukaemia $(n=1)$, Five $(17 \%)$ of the adult patients died. Among those were two patients aged 29 and 36 years with type $b$ infections and no known predisposing disease.

\section{$\beta$ lactamase producing strains}

Twenty nine strains $(6 \%$ ) (from 12 of the 24 counties) produced $\beta$ lactamase.

\section{Discussion}

Like all previous estimates of the incidence of $H$ influenzae meningitis in children ${ }^{1-10}$ the results of the present study are based on a retrospective search for patients; the true incidence of $H$ influenzae meningitis in Sweden is probably higher than that reported here. Some episodes of meningitis might never have been diagnosed, and some patients might have become ill abroad.

The incidence of $H$ influenzae meningitis in children aged 0-4 years in Sweden from 1981-1983 that we report $(31 / 100000$ /year) is higher than that previously reported in Europe ${ }^{6-10}-11-27 / 100000 /$ year. The incidence in Europe seems to be similar to or somewhat lower than that reported from white middle class North American populations, and considerably lower than in North American black and American Indian populations. ${ }^{1-5}$ The risk of developing $H$ influenzae meningitis in Sweden is, according to our data, $1 / 669$ before the age of 15 years.

The impact of invasive $H$ influenzae type $b$ disease on morbidity and mortality in children is considerable. The mortality from $H$ influenzae meningitis in Sweden is $1-2 \% .{ }^{10}$ The 11 fatal cases described here comprise $0.4 \%$ of all deaths (2822) in children aged $0-14$ years during the same time period; the mortality reported from other countries $(5-8 \%)$ is higher. $^{5-5}$

There were five children with serious neurological sequelae. The prevalence of less severe sequelae could not be estimated in this study, but other studies have described auditory impairment, mental retardation, motor abnormalities, visual impairment, language disorders, and behavioural or psychological problems, alone or in combination, in $27-33 \%$ of survivors. ${ }^{20-22}$ In addition children who seem to recover completely from meningitis have a lower mean intelligence quotient and perform less well than their siblings at intellectual and neurophysiological tests. ${ }^{23}{ }^{24}$ There are also other manifestations of $H$ influenzae infection, notably epiglottitis, which in Sweden seems to be more common than $H$ influenzae meningitis, ${ }^{25}$ septicaemia, pneumonia, osteitis, and arthritis.

The purified $H$ influenzae type b capsular polysaccharide vaccine could only have prevented $31-42 \%$ of the cases described here because it is only immunogenic in children over the age of 18 to 24 months. ${ }^{15} 16$ The experimental vaccines comprising the $H$ influenzae type $\mathrm{b}$ polysaccharide conjugated to proteins are of great interest as they will probably induce immunity from the age of 3 months. ${ }^{17-19}$

Although $H$ influenzae type b meningitis is mainly a disease of young children, the infection is also seen in adults. ${ }^{71-13}$ In the present study nine adults aged 17-55 years with no known predisposing diseases had $H$ influenzae type $\mathrm{b}$ meningitis, indicating that some apparently healthy adults in Sweden lack protective antibodies against $H$ influenzae type $b$. The finding of 17 infants born at term who got $H$ influenzae meningitis before the age of 3 months indicates that women of childbearing age in Sweden do not always have protective amounts of $H$ influenzae type $\mathrm{b}$ antibodies in their blood. There are many differences between $H$ influenzae meningitis in children and adults. In adults the disease is more often related to predisposing diseases and the mortality is high ${ }^{11-13}$; in the present study it was $17 \%$. In older patients with predisposing diseases non-typable strains of $H$ influenzae are also important pathogens as we have shown both here and previously. ${ }^{11-13}$

In conclusion, research into the prevention of invasive $H$ influenzae infections in children by immunisation should have a high priority because of the high incidence, the prevalence of sequelae, and the low but nevertheless important mortality.

We thank all the doctors who identified and provided information about patients with $H$ influenzae meningitis and also Jan Persson for help with computer processing of the data.

\section{References}

1 Ward J, Margolis HS, Lum MKW, Fraser DW, Bender TR. Haemophilus influenzae disease in Alaskan Eskimoes: characteristics of a population with an unusual incidence of invasive disease. Lancet 1981;i:1281-5.

2 Istre GR, Conner JS, Glode MP, Hopkins RS. Increasing ampicillin-resistance rates in Haemophilus influenzae meningitis. Am J Dis Child 1984;138:366-9.

3 Michaels RH, Schultz WF. The frequency of Hemophilus influenzae infections. Analysis of racial and enviromental factors. In: Sell SHW, Karzon DT, eds. Hemophilus influenzae. Proceedings of a conference on antigen-antibody system, epidemiology, and immunoprophylaxis. Nashville: Vanderbilt University Press, 1973:243-50.

${ }^{4}$ Losonsky GA, Santosham M, Sehgal V, Zwahlen A, Moxon R. 
Haemophilus influenzae disease in the White Mountain Apaches: molecular epidemiology of a high risk population. Pediatr Infect Dis 1984;3:539-47.

5 Coulehan JL, Michaels RH, Williams KE, et al. Bacterial meningitis in Navajo Indians. Public Health Rep 1976;91:464-8.

${ }^{6}$ Goldacre MJ. Acute bacterial meningitis in childhood. Lancet 1976;i:28-31.

7 Broughton SJ, Warren RE. A review of Haemophilus influenzae infections in Cambridge 1975-1981. J Infect 1984;9: $30-42$.

${ }^{8}$ Spanjaard L, Bol P, Ekker W, Zanen HC. The incidence of bacterial meningitis in the Netherlands-a comparison of three registration systems, 1977-1982. J Infect 1985;11:259-68.

9 Valmari P, Kataja M, Peltola H. Invasive Haemophilus influenzae and meningococcal infections in Finland. Scand $J$ Infect Dis 1987;19:19-27.

10 Claesson B, Trollfors B, Jodal U, Rosenhall U. Incidence and prognosis of Haemophilus influenzae meningitis in children in a Swedish region. Pediatr Infect Dis 1984;3:35-9.

11 Trollfors B, Claesson B, Lagergård T, Sandberg T. Incidence, predisposing factors and manifestations of invasive Haemophilus influenzae infections in adults. Eur $J$ Clin Microbiol 1984;1:180-4.

12 Simon HB, Southwich FS, Moellering RC, Sherman E. Haemophilus influenzae in hospitalized adults: current perspectives. Am J Med 1980;69:219-26.

${ }^{13}$ Spagnuolo PJ, Ellner JJ, Lerner PI, et al. Haemophilus influenzae meningitis: the spectrum of disease in adults. Medicine 1982;61:74-85.

14 National Central Bureau of Statistics. Official statistics of Sweden. Population part 3. Stockholm: National Central Bureau of Statistics 1981-1984.

15 Peltola H, Käyhty H, Sironen A, Mäkelä PH. Haemophilus influenzae type b capsular polysaccharide vaccine in children: $A$ double-blind field study of 100,000 vaccinees 3 months to 5 years of age in Finland. Pediatrics 1977;60:730-7.

${ }^{16}$ Cochi SL, Broome CV, Hightower AW. Immunization of US children with Haemophilus influenzae type $\mathrm{b}$ polysaccharide vaccine. JAMA 1985;253:521-9.
17 Eskola J, Käyhty H, Peltola $\mathrm{H}$, et al. Antibody levels achieved in infants by course of Haemophilus influenzae type b polysaccharide/diphtheria toxoid conjugate vaccine. Lancet 1985;i: 1184-6.

${ }^{18}$ Einhorn MS, Weinberg GA, Anderson EL, Granoff PD, Granoff DM. Immunogenicity in infants of Haemophilus influenzae type b polysaccharide in a conjugate vaccine with Neisseria meningitis outer membrane protein. Lancet 1986;ii: 299-302.

${ }^{19}$ Schneerson R, Robbins JB, Parke JC Jr, et al. Quantitative and qualitative analyses of serum antibodies elicited in adults by Haemophilus influenzae type $b$ and pneumococcus type $6 A$ capsular polysaccharide-tetanus toxoid conjugates. Infect Immun 1986;52:519-28.

20) Lindberg J, Rosenhall U, Nylén O, Rignér ̊̊. Long-term outcome of Haemophilus influenzae meningitis related to antibiotic treatment. Pediatrics 1977;60:1-6.

${ }^{21}$ Sell SHW, Merrill RE, Doyne EO, Zimsky EP Jr. Long-term sequelae of Haemophilus influenzae meningitis. Pediatrics 1972;49:206-11.

${ }^{22}$ Bohr V, Hansen B, Kjersem H, et al. Sequelae from bacterial meningitis and their relation to the clinical condition during acute illness, based on 667 questionnaire returns. J Infect 1983;7:102-10.

${ }^{23}$ Sell SHW, Webb WW, Pate J, Doyne EO. Psychological sequelae to bacterial meningitis: Two controlled studies. Pediatrics 1972 49:212-17.

${ }^{24}$ Taylor HG, Michaels RH, Mazur PM, Bauer RE, Liden CB. Intellectual, neuropsychological, and achievement outcomes in children six to eight years after recovery from Haemophilus influenzac meningitis. Pediatrics 1984;74:198-205.

${ }^{25}$ Claesson B, Trollfors B, Ekström-Jodal B, et al. Incidence and prognosis of acute epiglottitis in children in a Swedish region. Pediatr Infect Dis 1984;3:534-8.

Correspondence to Dr B Trollfors, Department of Pediatrics, Östra Hospital, S-416 85 Göteborg, Sweden.

Received 14 July 1987 